Available online at GSC Online Press Directory

GSC Biological and Pharmaceutical Sciences

e-ISSN: 2581-3250, CODEN (USA): GBPSC2

Journal homepage: https://www.gsconlinepress.com/journals/gscbps

(RESEARCH ARTICLE)

\title{
Prevalence of ESBL producing MDR E. coli and Klebsiellae pneumonae from clinical isolates of nosocomial hospital acquired infections
}

\author{
Bukhari Nain Taara ${ }^{1, *}$, Jameel Aqsa ${ }^{1}$, Yasmeen lashari ${ }^{2}$, Atiya Hussain ${ }^{3}$, Urooj M Ibrahim ${ }^{4}$, Anum Muneer \\ 5 and Shahana Urooj Kazmi ${ }^{1}$
}

${ }^{1}$ IIDRL lab Karachi University.

2 Dadabhoye institute of higher education.

${ }^{3}$ Bolan university of medical and health sciences Quetta.

Publication history: Received on 06 May 2020; revised on 14 May 2020; accepted on 16 May 2020

Article DOI: https://doi.org/10.30574/gscbps.2020.11.2.0131

\begin{abstract}
The impact of nosocomial infections (NIs) is an important public health concern due to emergence of new MDR strains of pathogens and approximately 5 to $10 \%$ of hospitalized patients are affected by NIs. 90,000 deaths per year in United States only warrant investigation. This study was a hospital based cross sectional study to determine the ESBL producing MDR nosocomial infection and their control from Jun 1st2016 to Dec31st 2017. 500 patients were investigated all demographic data was collected from patients with a history of hospital admission for $\geq 2$ days. In this study out of total 500 patients, $(62 \%)$ patients were female and (38\%) were males, $19 \%$ isolates were E.coli and $18 \%$ were K.pneumonae all were MDR along with other pathogens .most of strains were showing 55\%-85\% resistance for more than one antibiotics. PCR studies show that SHV (32\%) and TEM (18\%) genes were found in ESBLs producing organisms. Due to importance of ESBL producing organisms and difficult treatment of infections caused by these bacteria rapid identification of ESBL producing strains should be adopted in enterobacteraciae, infection control strategies are recommended to adopt and warrant investigation.
\end{abstract}

Keywords: MDR multidrug resistant; ESBL Extended spectrum of Beta Lactamase; NIs nosocomial infections; Pathogens; PCR polymerase chain reaction

\section{Introduction}

The impact of nosocomial infections (NIs) is an important public health concern due to emergence of new strains of antibiotic resistant pathogens [1,2]. Nosocomial infections (NIs) have increased and gained attention because of high isolation rates of multi drug resistant (MDR) organisms in admitted and out patients in hospitals with complicated infectious ailments [3,4]. The spread of multi drug resistant (MDR) bacteria into the community is crucial due to increased morbidity, mortality, healthcare costs and antibiotic use [5.6]. The main threat on the horizon is represented by Enterobacteraciae due to production of extended spectrum $\beta$-lactamases and is becoming increasingly prevalent in community [7.8]. It is reported that nearly a million people, or approximately 5 to $10 \%$ of hospitalized patients, are affected by nosocomial infections (NI) with a death rate of estimated 90,000 deaths per year in United States only, resulting high healthcare costs in managing nosocomial infections [9,10]. It is reported that 400,000 patients with hospital acquired infections (HAI) present with a resistant strain each year in Europe [11]. A prevalence survey in 2002 conducted by World Health Organization (WHO) showed an average of 8.7\% of hospital patients had hospital acquired infection (HAI) [12]. This alarming situation warrant investigation.

\footnotetext{
${ }^{*}$ Corresponding author: Bukhari Nain Taara
} 
The study was designed with specific objective to study the prevalence of nosocomial infection in public and private sector secondary, tertiary care hospitals and to identify the indigenous circulating ESBL producing MDR strains involved in nosocomial infections.

\section{Material and methods}

\subsection{Study area}

The study was conducted at Private General Hospital located in Pakistan in collaboration with department of Clinical Microbiology Department of Dadabhoye Institute of Higher Education and IIDRL lab of "University of Karachi".

\subsection{Study design}

This study was a hospital based cross sectional study to determine the ESBL producing MDR nosocomial pathogens and their control from Jun 1st 2016 to Dec 31st 2017.

\subsection{Sample size}

During this study duration of one and half year's almost 500 patients were investigated all demographic data was collected from patients with a history of hospital admission for $\geq 2$ days.

\subsection{Ethical considerations}

The proposal was approved by the ethical review committee of Hospital and Universities as well.

\subsection{Inclusion criteria}

All patients admitted in hospital reporting with some infection and developed another infection during hospitalization were included in this studied.

\subsection{Exclusion criteria}

Patient who came of some infection and they not develop new infection during this study were excluded.

\subsection{Recruitment of study subjects}

Study subjects were identified and recruited from OPD as well as certain wards from where most of MDR cases were reported, meeting the criteria and gave consent to participate were included in the study.

\subsection{Collection and transport of samples}

Clinical samples collected from patients were transported to the lab in duplicate with in 12 hour of collection. Samples include Urine, Blood, Stool, Body fluid and Pus were transported in separate plastic bags to lab for processing and for detection of bacterial pathogens causing infection.

\subsection{Isolation and characterization of bacterial pathogens}

Using standard methods (CLSI) guidelines the pathogens were cultured on Blood agar, MacConkey's agar, CLED (Cysteine lactose electrolyte deficient) agar, S.S (Salmonella Shigella) agar, Chocolate agar, SIM (Sulphur, indole and motility) medium, TSI (triple sugar iron) agar, Simon citrate agar and Urease medium. Antibiotic susceptibility tests were performed following Kirby Bauer disk diffusion test on Mueller Hinton agar. Susceptibility or resistance was tested against a panel of antimicrobial agents, which included AMC (Amoxicillin "10 $\mu \mathrm{g}$ "/Clavulanic acid), TZP (Tazobactam

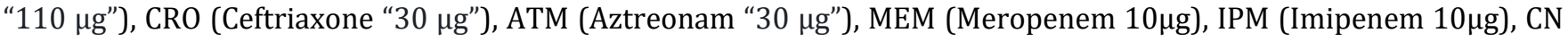
(Gentamicin "30 $\mu \mathrm{g}$ "), C (Chloramphenicol "30 $\mu \mathrm{g}$ "), SXT (Co-trimoxazole), SCF (Salbactam "30 $\mu \mathrm{g}$ "/ Cefoperazone "75 $\mu \mathrm{g}$ "), VA (Vancomycin "30 $\mu \mathrm{g}$ "), E (Erythromycin "15 $\mu \mathrm{g}$ "), AK (Amikacin "30 $\mu \mathrm{g}$ ") and CIP (ciprofloxacin "5 $\mu \mathrm{g}$ ") were used for the presence of enteric bacterial pathogens such as: Acinetobacter sp. Citrobacter freundii, Enterobacter $s p$. Escerichia coli, Klebsiella pneumonia, Morganella morganii, Proteus Vulgaris, Proteus mirabilis, Pseudomonas aeruginosa, Pseudomonas sp. Salmonella typhi, staphylococcus aureus, and streptococcus pneumonia by culture technique.

All inoculated media plates were incubated at $37^{\circ} \mathrm{C}$ for 24 hours. Any bacterial growth was identified by gram staining and standard set of biochemical tests in addition to bacterial colonies morphological characteristics. 


\subsection{Statistical analysis}

All data collected was analyzed using SPSS version 16.00. Pie and bar chart were also used to present the descriptive summary of the variables in graphical way.

\subsection{Antibiotic susceptible of nosocomial bacterial isolated}

Susceptibility testing was performed on isolates based on the Kirby Bauer Disc diffusion technique. [12]. The grades of susceptibility pattern were recognized as sensitive, intermediate and resistant by comparison of the zone of inhibition as indicated in Clinical laboratory and CLSI Guidelines. MDR was defined as acquired non-susceptibility to at least one agent in three or more antimicrobial categories. [13].

\subsection{Molecular characterization of nosocomial bacterial isolate}

\subsubsection{DNA extraction}

DNA extraction following this method was performed. Individual isolated colony from Mac Conkey's agar was inoculated into sterile nutrient broth. After overnight incubation (18-24 hours) the broth was sub-cultured for purity and simultaneously $1.5 \mathrm{ml}$ broth was used for DNA extraction. Briefly $1.5 \mathrm{ml}$ of turbid broth was transferred to sterile eppendorf vials and centrifuged at 10000 RPM for 10 minutes. The supernatant i.e. clear broth was discarded while the pellet was used for the extraction of DNA. For DNA extraction kit was used. Briefly the pellet was suspended in "200 $\mu \mathrm{l}$ " of PBS followed by addition of " $50 \mu \mathrm{l}$ " of Lysozyme. The tube was then incubated at $37^{\circ} \mathrm{C}$ for $15 \mathrm{~min}$. After incubation lysis buffer " $400 \mu \mathrm{l}$ "and proteinase $\mathrm{K}$ ( $40 \mu \mathrm{l}$ " of " $10 \mathrm{mg}$ " $/ \mathrm{ml}$ ) were added and incubated for 10 minutes at $70^{\circ} \mathrm{C}$ after vortexing. The whole lysate was transferred into Pure Fast spin column and centrifuged at $10000 \mathrm{rpm}$ for $1 \mathrm{~min}$. The flow through was discarded and washing was performed two times using " $500 \mu \mathrm{l}$ " of Wash Buffer followed by centrifugation at $10000 \mathrm{rpm}$ for 1 minute. After washing flow through was discarded and the column was centrifuged for 2 minutes to remove any residual ethanol. DNA elution was performed by adding $100 \mu$ l of elution buffer in the column followed by centrifugation for $1 \mathrm{~min}$. " $1 \mu \mathrm{l}$ ” of extracted DNA was used for PCR amplification.

\subsubsection{Polymerase chain reaction for TEM \& SHV amplification}

All identified E.coli and Klebsiella pneumonia were further characterized by using modern PCR technique, primers were used for molecular characterization of pathogenic strains.

\subsubsection{Steps in PCR}

The PCR procedure consists of following steps,

- " $25 \mu \mathrm{l}$ " of reaction mixture contained "3 $\mu \mathrm{l}$ ” of template DNA, " $1 \mu \mathrm{l}$ ” $\mathrm{MgCl}_{2}$, "0.17 $\mu \mathrm{l}$ ” of each primer,

- 1 unit of Tag DNA polymerase, “0.5 $\mu \mathrm{l}$ ” dNTP Mix, "2 $\mu \mathrm{l}$ ” 10× PCR buffer and "17 $\mu \mathrm{l}$ ” dd $\mathrm{H}_{2} \mathrm{O}$.

- The reaction mixtures in the initial denaturation stage were heated at $96^{\circ} \mathrm{C}$ for five minutes and were amplified for 30 cycles using a gradient master cycler (Eppendorf, Germany)

- Each cycle was comprised of denaturation at $94^{\circ} \mathrm{C}$ for 30 seconds, annealing at $55^{\circ} \mathrm{C}$ and $53^{\circ} \mathrm{C}$ for 30 seconds, and extension at $72^{\circ} \mathrm{C}$ for one minute.

- The final extension was performed at $72^{\circ} \mathrm{C}$ for seven minutes.

\section{Results}

In this study a total of 500 patients from January 2016 to June 2017, who developed with the nosocomial infection were recruited their samples were collected and transported to laboratory, processed and analyzed. Demographic data analysis showed that out of 500 samples from patients attending out door unit and hospitalized in Public and Private sector hospitals, (62\%) patients were female and (38\%) were males, who presented with MDR nosocomial infection.

Table 1 Basic information of studied sample gender

\begin{tabular}{lll}
\hline Gender & $\mathbf{N}$ & $\mathbf{\%}$ \\
\hline Female & 340 & 62 \\
Male & 160 & 38 \\
Total & 500 & 100 \\
\hline
\end{tabular}


Table 2 Sample specimen in percentages

\begin{tabular}{lll}
\hline S\# & Sample Types & N \\
\hline 1 & Urine & $36 \%$ \\
2 & Stool & $17 \%$ \\
3 & Blood & $30 \%$ \\
4 & Body Fluid & $7 \%$ \\
5 & Pus swab & $10 \%$ \\
\hline
\end{tabular}

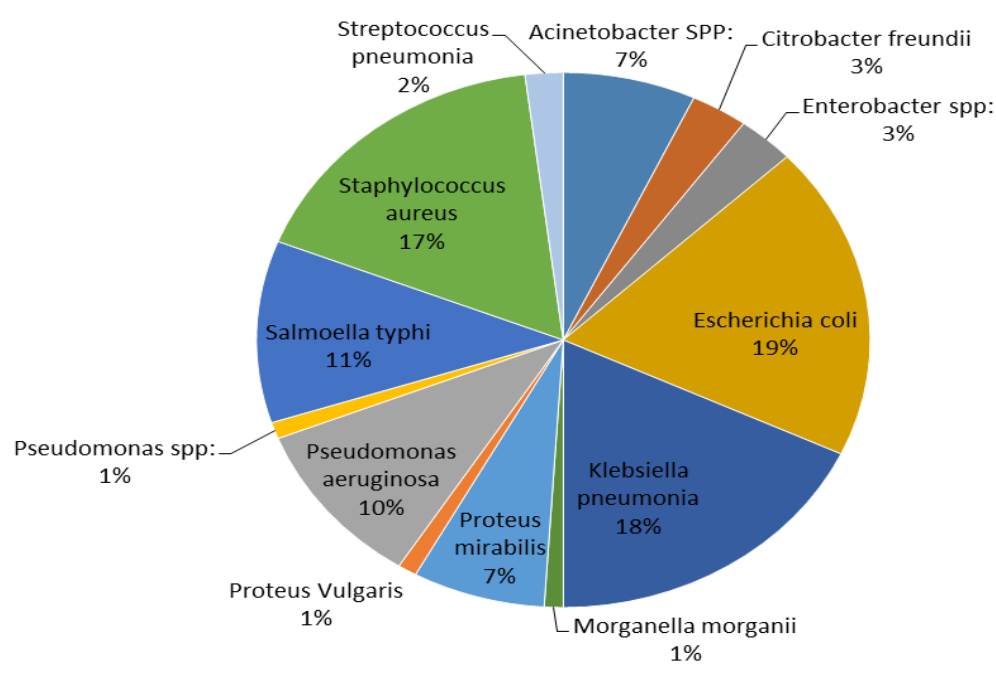

Figure 1 Spectrum of bacterial pathogens isolated from patients with nosocomial infection

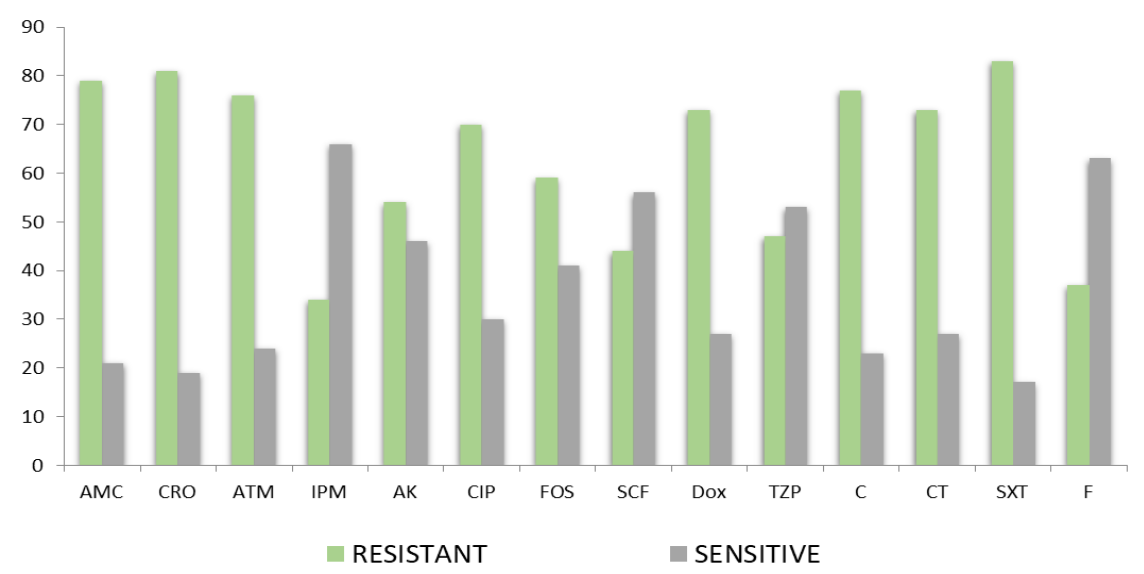

Figure 2 Antibiotic susceptible of gram negative nosocomial bacterial isolates

\section{TEM and SHV gene}

In PCR method the distribution of TEM and SHV genes in isolated ESBLs producing organisms was analyzed. All E.coli and Klebsiella pneumonia were selected for PCR for identification of TEM and SHV genes. Isolates having both TEM and SHV genes were common (75.3\%) whereas only 15 per cent isolates possessed TEM gene and 7.4 per cent SHV gene alone. 
Table 3 List of Primers

\begin{tabular}{llll}
\hline Primer & \multicolumn{1}{c}{ Primer sequence } & Amplicon size (bp) & reference \\
\hline SHV & 5'-TCAGCGAAAAACACCTTG -3' (FORWARD PRIMER) & 1016 & $(12)$ \\
& 5'-CCCGCAGATAAATCACCA -3' (REVERSE PRIMER) & & \\
TEM & 5'-GAGTATTCAACATTTCCGTGTC -3' (FORWARD PRIMER) & 717 & $(12)$ \\
& 5'-TAATCAGTGAGGCACCTATCTC -3' (REVERSE PRIMER) & & \\
\hline
\end{tabular}

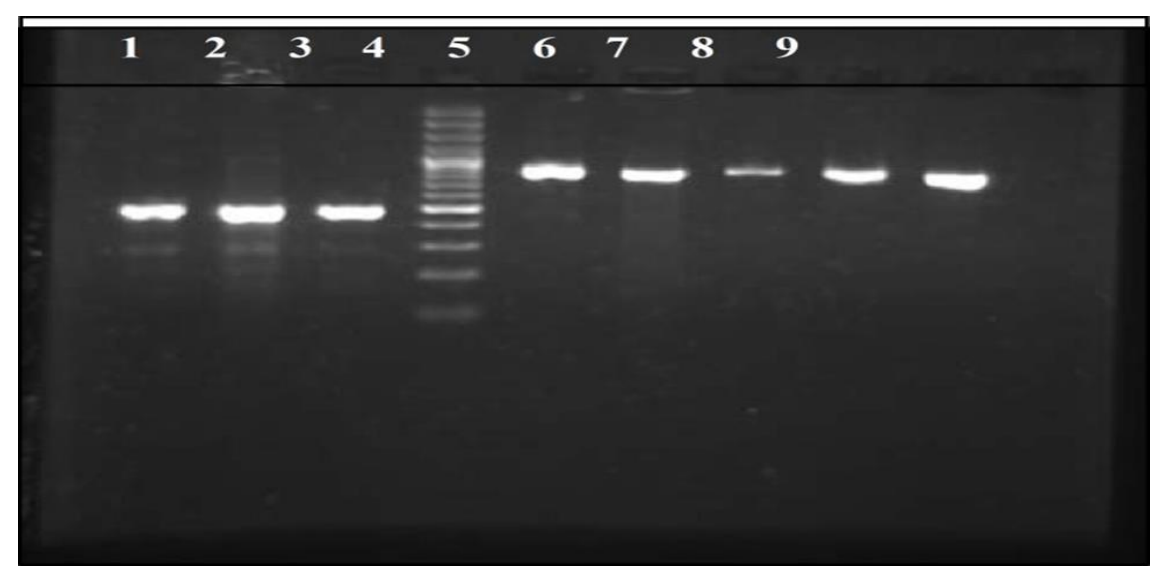

Figure 3 PCR Results for SHV and TEM genes

Lane number 1, 2 and 3 are showing 471bp fragment of SHV gene .Lane number 5-9 are showing 861 bp fragment of TEM gene and lane 4 is showed the 100 bp DNA size marker.

Table 4 The prevalence of TEM and SHV gene in ESBLs producing organisms in hospitalized patients and out-patients.

\begin{tabular}{|c|c|c|c|c|c|c|c|c|c|}
\hline \multirow[t]{2}{*}{ E.coli } & \multicolumn{8}{|c|}{ Klebsiella pneumoniae } & \multirow[t]{2}{*}{ Total } \\
\hline & $\begin{array}{l}\text { TEM } \\
\text { positive }\end{array}$ & $\begin{array}{l}\text { SHV } \\
\text { positive }\end{array}$ & $\begin{array}{l}\text { TEM and } \\
\text { SHV } \\
\text { positive }\end{array}$ & $\begin{array}{l}\text { TEM and } \\
\text { SHV } \\
\text { negative }\end{array}$ & $\begin{array}{l}\text { TEM } \\
\text { positive }\end{array}$ & $\begin{array}{l}\text { SHV } \\
\text { positive }\end{array}$ & $\begin{array}{l}\text { TEM and } \\
\text { SHV } \\
\text { positive }\end{array}$ & $\begin{array}{l}\text { TEM and } \\
\text { SHV } \\
\text { negative }\end{array}$ & \\
\hline $\begin{array}{l}\text { Admitted } \\
\text { patients }\end{array}$ & 18 & 5 & 6 & 5 & 4 & 9 & 15 & 7 & 69 \\
\hline $\begin{array}{l}\text { Outdoor } \\
\text { patients }\end{array}$ & 7 & 2 & 3 & 5 & 4 & 3 & 6 & 5 & 35 \\
\hline Total & 25 & 7 & 9 & 10 & 8 & 12 & 21 & 12 & 104 \\
\hline
\end{tabular}

\section{Discussion}

Infection control measures or scheduled surveillance can reduce the incidence of nosocomial infections [12, 13]. Epidemiological studies showing data regarding the burden and existing resistance mechanisms, more than 2 million people or $5 \%$ to $10 \%$ of hospitalized patients are affected by nosocomial infections with an estimated 90,000 deaths with overall 29\% mortality rate every year [13]. The mortality rate of our trauma/ surgical intensive care unit patients $(27.3 \%)$ was higher than Thailand (20\%) [130]. Where as in Ethiopia, the mortality rate was (9\%) among admitted patients (aged 21-30 years old) [14]. This difference in resistance rates between Asian and European countries may be attributed to the presence of effective infection control policies, antibiotic resistance containment program, better regulation of drug production, restricted prescription and sale of antibiotics, however emergence and dissemination of multi-drug resistant strains among enterobacteraciae like (ESBL) ß-lactamase producing E. coli, K. pneumonia, and many others is alarming and matter of concern. Severe consequences arise causing high medicine resistance, hospitalization cost and mortality of patients. According to demographic data analysis showed that male to female ratio (76\%-33\%) is very significant (Table No.2)as more number of females patients were enrolled in this study most 
probably due to frequent urinary tract infection (UTI) and gynecological problems among them. It was much lower in other reported studies from developed countries where almost 30\% registered patients were female, where as in developing countries ratio is high probably due to low socioeconomic and low personal hygienic profile .The E.coli and K.pneumoniae were isolated more frequently when HAI are concerned they, are rated fourth and fifth most common reason of pneumonia and blood stream infections in Intensive care units, neonatal units and among immune compromised patients [15]. The organism's potential to survive and colonize in hospital environment is linked to ESBL production the results does not correlate with the reported studies from developed countries where mostly sick persons acquiring nosocomial infections are more than 60 years of age [6,7]. Almost in $75 \%$ to $90 \%$ of the cases E.coli remains the leading cause in those patients who were hospitalized with a complicated urinary tract infection (UTI) and other ailments showing high resistance rate against commonly prescribe drugs. In this study (19\%) E. coli were reported having high level of resistance rate (35\% - 87\% Figure No1, 2) against Augmentin, Ceftriaxone, Azethroneam, Ciprofloxacin, Domiciling, Chloramphenicol, Celestin and Cotrimexazole (Fig No.2). The most probable reason might be the overuse of antibiotics in other ailments where it is not recommended as in viral and parasitic infections. In this study 18\% K. pneumoniae ( Fig No.1) considered to be responsible for (94 - 26\%) of all hospital acquired urinary tract infections blood stream infections globally increasing resistance trends reported to multi Studies from both developed and developing countries [18,19]. Regarding the epidemiology of extended spectrum Beta Lactamase (ESBL) producing K. pneumoniae and E.coli our findings are consistent with other studies [16].

In this study the ESBLs producing organisms (E. coli and K. pneumoniae) were also positive for SHV (32\%) and TEM $(18 \%)$ genes and the frequency of SHV gene was higher than TEM gene that was different from results of another study [17]. However, further studies are required for finding the other genes in ESBLs producing $E$. coli and $K$. pneumoniae bacteria. ESBLs production monitoring is recommended to avoid treatment failure and suitable infection control in increasing drug resistance $[18,19]$.

\section{Conclusion}

Time for life saving antibiotics is running out due to resistance acquiring mechanisms. Antibacterial research and development pipelines are nearly dry, emergence and spread of MDR bacteria is fast. Due to importance of ESBL producing organisms and difficult treatment of infections caused by these bacteria rapid identification of ESBL producing strains should be adopted in enterobacteraciae, infection control strategies are recommended to adopt and warrant investigation.

\section{Compliance with ethical standards}

\section{Acknowledgments}

This study was conducted with cooperation of IIDRL lab of University of Karachi with the permission of ethical review committee permission.

\section{Disclosure of conflict of interest}

It is declare that there is no conflict of intrest among authors regarding this research article.

\section{Statement of ethical approval}

The present research work was conducted after the approval of ethical review committee of Dadabhoye institute of higher education as well from public hospital where patients were recruited

\section{Statement of informed consent}

Informed consent was taken by patient or by attendant.

\section{References}

[1] Allegranzi B, Nejad SB, Combescure C, Graafmans W, Attar H, Donaldson L and Pittet D. (2011). Burden of endemic health-care-associated infection in developing countries: systematic review and meta-analysis. The Lancet, $377(9761), 228-41$.

[2] Khan HA, Ahmad A and Mehboob R. (2015). Nosocomial infections and their control strategies. Asian pacific journal of tropical biomedicine, 5(7), 509-14. 
[3] Brusaferro S, Arnoldo L, Cattani G, Fabbro E, Cookson B, Gallagher R, Hartemann P, Holt J, Kalenic S, Popp W and Privitera G. (2015). Harmonizing and supporting infection control training in Europe. Journal of Hospital Infection, 89(4), 351-6.

[4] Garner JS, Jarvis WR, Emori TG, Horan TC and Hughes JM. (1988). CDC definitions for nosocomial infections, 1988. American journal of infection control, 16(3), 128-40.

[5] Custovic A, Smajlovic J, Hadzic S, Ahmetagic S, Tihic N and Hadzagic H. (2014). Epidemiological surveillance of bacterial nosocomial infections in the surgical intensive care unit. Materia socio-medica, 26(1), 7.

[6] Llor C and Bjerrum L. (2014). Antimicrobial resistance: risk associated with antibiotic overuse and initiatives to reduce the problem. Therapeutic advances in drug safety, 5(6), 229-41.

[7] Haas JP. (2006). Measurement of infection control department performance: state of the science. Am J Infect Control, 34(9), 543-9.

[8] Mayhall GC. (2003). The epidemiology of burn wound infections: then and now. Clin Infect Dis, 37, 543-50.

[9] Chandrasekar PH, Kruse JA and Mathews MF. (1986). Nosocomial infection among patients in different types of intensive care units at a city hospital. Critical care medicine, 14(5), 508-10.

[10] Baqi S, Damani NN, Shah SA and Khanani R. (2009). Infection control at a government hospital in Pakistan. International Journal of Infection Control, 17, 5(1).

[11] World Health Organization. (2014). Antimicrobial resistance: global report on surveillance. World Health Organization.

[12] Wellington EM, Boxall AB, Cross P, Feil EJ, Gaze WH, Hawkey PM, Johnson-Rollings AS, Jones DL, Lee NM, Otten $\mathrm{W}$ and Thomas CM. (2013). The role of the natural environment in the emergence of antibiotic resistance in Gramnegative bacteria. The Lancet infectious diseases, 13(2), 155-65.

[13] Zivanovic V, Gojkovic-Bukarica L, Scepanovic R, Vitorovic T, Novakovic R, Milanov N, Bukumiric Z, Carevic B, Trajkovic J, Rajkovic J and Djokic V. (2017). Differences in antimicrobial consumption, prescribing and isolation rate of multidrug resistant Klebsiella pneumoniae, Pseudomonas aeruginosa and Acinetobacter baumannii on surgical and medical wards. PloS one, 12(5), e0175689.

[14] Solomon FB, Wadilo FW, Arota AA and Abraham YL. (2017). Antibiotic resistant airborne bacteria and their multidrug resistance pattern at University teaching referral Hospital in South Ethiopia. Annals of clinical microbiology and antimicrobials, 16(1), 29.

[15] Sader HS, Farrell DJ, Flamm RK, et al. (2014). Antimicrobial susceptibility of Gram-negative organisms isolated from patients hospitalized with pneumonia in US and European hospitals: results from the SENTRY Antimicrobial Surveillance Program, 2009-2012. Int J Antimicrob Agents, 43, 328-334.

[16] Beceiro A, Tomás M and Bou G. (2013). Antimicrobial resistance and virulence: a successful or deleterious association in the bacterial world? Clin Microbiol Rev, 26, 185-230.

[17] Simor AE, Farley JE and Carroll KC. (2011). Genotypic and phenotypic characterization of methicillin-susceptible Staphylococcus aureus isolates misidentified as methicillin-resistant Staphylococcus aureus by the BD GeneOhm MRSA assay. J Clin Microbiol, 49, 1240- 1244.

[18] Wintermans BB, Reuland EA, Wintermans RG, et al. (2013). The cost-effectiveness of ESBL detection: towards molecular detection methods? Clin Microbiol Infect, 19, 662-665.

[19] Fujita S, Yosizaki K, Ogushi T, et al. (2011). Rapid identification of gram-negative bacteria with and without CTX$\mathrm{M}$ extended-spectrum $\beta$-lactamase from positive blood culture bottles by PCR followed by microchip gel electrophoresis. J Clin Microbiol, 49, 1483-1488.

\section{How to cite this article}

Dr. Bukhari NT, Jameel A, Dr. Yasmeen l, Atiya H, Urooj MI, Anum M and Dr. Shahana UK. (2020). Prevalence of ESBL producing MDR E. coli and Klebsiellae pneumonae from clinical isolates of nosocomial hospital acquired infections. GSC Biological and Pharmaceutical Sciences, 11(2), 175-181. 